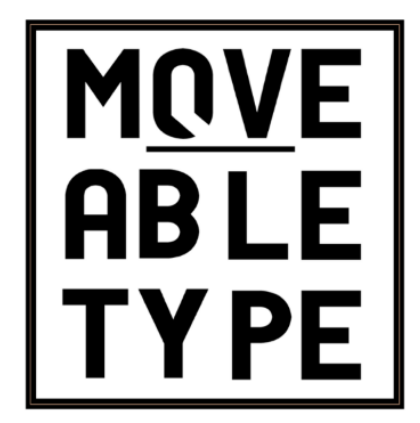

Article: The Messy Making of David Jones's Anathemata

Author[s]: Paul Stanbridge

Source: MoveableType, Vol. 5, 'Mess' (2009)

DOI: $10.14324 / 111.1755-4527.043$

MoveableType is a Graduate, Peer-Reviewed Journal based in the Department of English at UCL.

(C) 2009 Paul Stanbridge. This is an Open Access article distributed under the terms of the Creative Commons Attribution License (CC-BY) 4.0https://creativecommons.org/licenses/by/4.0/, which permits unrestricted use, distribution, and reproduction in any medium, provided the original author and source are credited.

\title{
UCLPRESS
}




\section{The Messy Making of David Jones's Anathemata}

In May 1938, David Jones (1895-1974) compared a new project he was just beginning with his long narrative war poem, In Parenthesis, published in the previous year:

I don't know if any of it is any good. A very rambling affair - sometimes it all seems balls and sometimes I like it in places. But I.P. was chained to a sequence of events which made it always a straightforward affair, whereas this effort is, I fear, about 'ideas'[.] $]^{1}$

Here, Jones is concerned not with the experience of narrative as a reader but with the construction of narrative as an artist: In Parenthesis was 'a straightforward affair' because it was in that poem's writing that Jones was 'chained to a sequence of events' - those he experienced during his own march across Normandy to fight on the Western Front. The problem of this mode of production for a poem about ideas is not the 'chains'. For Jones, a connection to some overall principle is an essential prerequisite for freedom of action, as we see from his comments about the etymology of religion that he favours (from ligio, the source of MnE 'ligament'): 'It [religion] refers to a binding, a securing. Like the ligament, it secures a freedom to function. The binding makes possible the freedom. Cut the ligament and there is atrophy'. Narrative structure is foreclosed as a form for a poem about ideas because it presents a sequence of events, and Jones's ideas were not conducive to an orderly and logical laying out. In the course of the fifteen-year period of the writing of The Anathemata (1952), Jones's increasingly complex interrelation of ideas informed the necessary development of a method of writing which would not reduce this complexity into a false coherence. Jones needed to develop a new kind of 'chain', one that would not be an imposition on the process by which these ideas became poetry. This essay explores the development of the method that enabled the writing of The Anathemata in order to reappraise Jones's achievement.

\section{'I can't see how it works': the ideas behind The Anathemata}

The ideas that informed the writing of The Anathemata form the subject of much of Epoch and Artist (1959), a collection of essays written by Jones between 1937 and 1958. In the seminal essay of this collection, 'Art and Sacrament' (1955), Jones continually reminds us that his sole intention is to explore the problems he experiences in his daily work. ${ }^{3}$ At the conclusion of the essay, Jones can only reemphasise the 'dilemmas which show themselves to underlie some of the problems discussed in this present essay of enquiry' ( $E \& A 179)$. 
He never explicitly seeks to resolve the problems which arise in his discussion for a reason; as he states in the Preface to The Anathemata, 'I do not raise these questions in order to answer them, for I do not know what the answers may be'. 'Art and Sacrament' is an aporetic text: it explores the nature of the aporia - 'a perplexing difficulty' according to the Oxford English Dictionary, but by the implications of its etymology also the far more Jonesian (because paradoxical) 'impassable path' which prevents a systematic resolution of the issues which form the basis of its investigation. The aporetic method, systematized by Aristotle in The Metaphysics, forms the instinctive basis of Jones's investigation; he is perplexed by the nature of the arts in modernity (he is in a state of aporia) and seeks in the course of the essay to establish what is causing this perplexity (what the aporiai are). In other words, Jones seeks as a first step to move from a state of puzzlement to a statement of the puzzle.

The central aporia in Jones's thought resides in the conflict between his conception of the nature of man as man-the-maker and the difficulty of man fulfilling this role in modernity. According to Jones, man's makings have throughout all times incorporated both utile and gratuitous elements (see $E \& A$ 176-7). The utile element of a making is purely animalic; wholly utile works - birds' nests and beehives, diesel engines and screwdrivers - are wholly mundane. On the other hand, the gratuitous element of a making is seen by Jones as an engagement with ontological truth because the necessity directing that making is immaterial: there is no reasonable justification for making such works. Jones groups the consecration of the Eucharistic bread and wine, the painting of a landscape, the writing of a poem, and the giving of flowers to one's sweetheart together under the catch-all term 'sacrament'. The making of sacraments material signs for immaterial realities - is an activity peculiar to man. The gratuitous element which appears both to inhere to and enable the production of sacraments is seen by Jones as in some unknown way necessarily an assertion of the reality of a metaphysical presence: 'it is on account of the anthropic sign-making that we first suspect that anthropos has some part in without-endness' ( $E \& A 156)$. The act of making is the originary and defining act of man. The very first line of The Anathemata presents this interdependence most effectively: 'We already and first of all discern him making this thing other' (Ana 49). In other words, at the moment a primate first made a sign (or sacrament) of something other - which is to act with a measure of gratuitousness - that primate became a human being.

The crux of the problem in Jones's thought is that, in the current technocracy, man is in danger of feeling only a utilitarian compulsion to make things, which means that sacrament - and thus art, religion and love - is in danger of extinction. And if this is the case, so too must be man. Man in modernity seems to be both man and not-man: man, being defined and coming into existence as man-the-gratuitous-maker however many millennia ago, is in modernity not-man-the-utile-maker. Jones states this fundamental, over-arching aporia thus:

If we deny that man is man-the-artist, man the sacrament-maker, etc., we deny 
the existence of man and if we continue to believe in the existence of this man we find it difficult to account for these [wholly utile] qualities that now characterize the works of man. ( $E \& A 182)$

The 'specific task' of the artist is 'to lift up valid signs' (Ana 22), and yet the combination of, first, a declining shared cultural-historical knowledge, and second, a growing incursion of the instruments of technological progress into everyday life, is rapidly depleting the artist's sign-hoard. To summarize Jones's view: in reference to the first, the words 'wood' and 'chair' carry fewer and fewer undertones and overtones because, in the post-Christian West, Christ's cross and the ecclesiastical uses of the cathedra are not common cultural currency (see Ana 23-24); in reference to the second, a light bulb is not a 'valid sign' in the way that candlelight is because its use as sign precludes the re-calling of any time prior to the late nineteenth century when lightbulbs began to be used and so entered culture; equally, the artist who reverts to the old sign and uses candlelight produces an anachronistic art object - his artworks lack a necessary 'now-ness'.

The result is that Jones is unable to explain how the artist can exist in the present technocracy:

How are we to reconcile man-the-artist, man the sign-maker or sacramentmaker with the world in which we live today? [...] However one tries to express it one leaves much unsaid or puts it in such a way as to invite valid objections. (E\&A 176)

Jones expresses this affliction of a lack of clarity in thought in a letter to Harman Grisewood, written at the end of the year in which 'Art and Sacrament' was published, where he tells how, during an X-Ray examination he had recently had:

...one could ponder on the beneficent gadget-world and consider for a millionth time the work of the 'utile' and the world of 'sign' without getting any nearer a solution. I'm still stuck on that problem - I can't see how it works. (DGC 164-5)

To return to the letter from which I quoted at the beginning of this essay, we can now see how being chained to a sequence would not allow the writing of a work about such aporetic ideas. Any formal structure conceived in the early stages of writing would have become a kind of law, tidying up and compartmentalizing these unresolved ideas, refining them out of existence - a thing Jones might desire, but also an illusion. Aporia, paradox, illogic, mess - this is the reality for which Jones seeks a new method of writing in his early experiments. Clues as to what this method might involve are already discernible later in the same letter.

[I]f you haven't got a kind of racial myth expressed in war to write about and 
don't know about our old friend 'love' and are not interested in 'making a story', it seems all you can do is to ramble on about the things you think about on the whole all the time, and that is what I think this is about...it seems to me that if you just talk about a lot of things as one thing follows on another, in the end you may have made a shape out of all of it. That is to say, that shape that all the mess makes in your mind. (DGC 86)

The things which Jones thought about on the whole all the time were certainly the aporetic ideas already outlined, but they were also what he called his 'deposits', the elements of his inherited cultural history. The difficulty of writing from within an aporetic impasse about the history of culture is clear from Jones's uncertainty as to how he should proceed. A lack of awareness of the trajectory of his making appears to characterize his emerging method: he doubts both the subject of his poem ('what I think this is about') and the possibility of achieving a satisfactory form ('may have made a shape'). Intricated in the act of writing, then, is risk: 'It's a fearsome job may be all balls,' Jones writes in a later letter (written in November 1944; DGC 128). But he unequivocally states in the earlier letter that the poem, if realized, will be the shape of mess. This is itself an apparent paradox, for how can mess have a shape? Surely mess is defined by its lack of shape, because shape implies pattern or form? But this mess had precisely the shape which eluded a laying out in spatio-temporal or logical terms, involving his aporetic ideas and a sense of the complexity of the history of culture: together with his aporetic philosophy of man was his experience of his cultural inheritance as a 'great confluity and dapple, pied, fragmented, twisted, lost: that is indeed the shape of things all over Britain' ( $E \& A 46)$. Again, a barely graspable heterogeneous shape - but a shape nevertheless - presents itself to Jones.

There is one final underlying aspect to Jones's working life which requires consideration; Jones's feeling for that which enclosed his ideas and cultural history: being itself. Here it is, we might imagine, that the artist is presented with the problem that is and always has been also his or her motivating force: the representation of being in a different mode. In a letter to Harman Grisewood of May 1962, Jones writes of "the "mystery" or "subtlety" or "illusiveness" or "fragility" or "waywardness" or "complexity" or "fancifulness" etc.' that 'chaps' find in his paintings. He then continues thus:

It isn't the artist's 'fancy' or 'imagination' that imposes these qualities on a work - the blasted stuff is there as plain as a pikestaff - the bugger of it is how to 'transubstantiate' these qualities into whatever medium one is using, whether paint or words or whatever. It's only about once in a hundred times that one can come near to doing this. (DGC 189)

In an unpublished experimental fragment out of which The Anathemata grew, Jones presents the function common to a number of art objects: 
to show in this little / what gradation \& tangle of being / the school-doctors please ef $<$ to $>$ call order. ${ }^{6}$

In Jones's formulation, the artist approaches being with perhaps more sensitivity to its complexity than even the medieval scholastic philosophers he revered. True to the dictum of by far the most important figure in Jones's intellectual and aesthetic development, the leading twentieth century neo-scholastic, Jacques Maritain: 'poetry is ontology'.

\section{Mess Theory: Giving Chance a Chance}

So, the mess in Jones's mind, that which he is attempting to give material form in poetry, is an amalgam of the intricacies of his philosophy of man, his sense of cultural history, and his view of art as ontological engagement: a complex of aporia, dapple, and tangle. A question arises here about how to look at such ungraspable and messy ways of thinking, one with which David Trotter's book, Cooking With Mud can help us. In this study, Trotter begins by pondering the almost complete absence of any precedent concern with mess in cultural criticism.

The idea of mess has not attracted a great deal of attention. One reason for its relative neglect may be that it interferes in some way with the ascription to experience of meaning and value: a habit so widespread and so deeply felt it might almost be regarded as human necessity. ${ }^{8}$

Trotter goes on to delineate exactly how the idea of mess interferes with such a habit of thought:

A creature of this habit, I have already begun to investigate the meanings and values the idea of mess might be said to ascribe to experience: the grace it fleshes out, the mortal bone it cuts to. But the meanings and values thus ascribed are ones which envisage the very limit of meaning and value itself. The version of their own habit they most fiercely resist, both in descriptions of experience in general, and in descriptions of the history of culture in particular, is the most widespread and deeply felt of all: a determinism hellbent on the excavation of cause from effect. ${ }^{9}$

Mess asserts an absence of meaning and value because, without explanation or intent, it appears simply to happen; it posits a total freedom which human thought has always struggled to allow to remain totally free. ${ }^{10}$ Thus mess, as a visible symptom of invisible and ungraspable contingency, presents itself as a tool for the investigation of what contingency might mean.

Determinism is never not productive, and we should be thankful for the 
bounty it brings. But the hardest thing of all to think about is chance, which denies the very form and purpose of thought itself. Mess makes this possible. ${ }^{11}$

Within the terms of this formulation - where determinism and its absence gather to themselves, respectively, meaning and value and their absence - Trotter employs the idea of mess in the course of his study in a multitude of subtly different ways in order to explore how writers and artists, and so their cultures, felt for contingency. I find this formulation useful for looking specifically at David Jones's process of writing The Anathemata for one dominant reason.

The current and accepted account of how The Anathemata was written places itself safely at the very heart of a deterministic way of thinking about literary production. In a faultlessly efficient and self-validating movement between cause and effect, Jones is said to have achieved in the form of his poem (its effect) a sign for his worldview (its cause). As we shall see, this reading relies on reducing the mess of Jones's poem and the mess of his ideas into order, which is exactly the eventuality Jones avoided through the development of his method of writing the poem. There is at play a twofold determinism in relation to literary form here: first there came the deterministic writing of the poem; following this, criticism makes a deterministic reading of that form. The critics who have explored the process by which the poem was written find that their and Jones's determinisms coincide; this co-incidence pivots on those critics' assured discovery of the intended form of the poem. The location of Jones's intended meaning validates the construction of a conception of the intended form, which entrenches a reading of his intended meaning, and so on.

If Jones's intention can be located, his achievement can be measured - I see this as an important motivating aspect behind this intention-focused critical manoeuvre. However, the result - that Jones can be judged to be a great and thus underrated writer - is problematic: the systems of determinism, creative and critical, which underpin the measurement of Jones's achievement involve exactly the reductive or systematic mode of thinking which the process of the making of Jones's poem endeavoured to escape. One of my purposes in this essay is to try to tease out an alternative way of evaluating Jones's making, one which does not posit the meaning of the work and the value of Jones as its creator only by recourse to such a deterministic approach. The way in which I have done this is to look at the mess of the manuscript of The Anathemata; and the effect of this is that the role of chance, a role which subverts the existing teleological, intentionalist view of Jones's process of making, is crucial to that making. Far from undermining attempts to proclaim David Jones the equal of Joyce, Eliot and Pound (Eliot himself grouped together this quartet in his Preface to the second edition of In Parenthesis in 1963), I will suggest in this specific case that chance, perhaps uniquely, is replete with meaning and value through being a function through which the artist is most able to approach gratuitousness in the process of a making; and, as we have seen, gratuitousness is a foundational 
attribute of the foundational action (making) of man in Jones's thought.

\section{The Deterministic Discovery of the Form of The Anathemata}

Most Jones scholars, when discussing the form of The Anathemata, use a spatial metaphor. ${ }^{12}$ The two scholars who refer to the manuscripts of The Anathemata, Thomas Dilworth and Thomas Goldpaugh, find in them justification for their own take on the spatial form of the poem: the former, a series of concentric rings; the latter a unicursal labyrinth. This difference of metaphor, although signifying a different intention on the part of Jones, does not indicate a different take on the making of the poem, which in both cases is seen as formally intentioned. Dilworth describes how as readers we move from the opening of the poem at a Roman Catholic Mass, through a number of separate actions in the poem to its centre, and thereafter retrace our steps, revisiting each of those actions in reverse order. Thus, at the end, we are back where we began: at the Mass. Directly within this outer parenthesis concerned with the Mass is another parenthesis, which concerns itself with dating the Last Supper and Crucifixion in relation to historic and prehistoric events; directly within this is another, where we attend the sailing to port of an ancient ship; and so on. Dilworth identifies eight parentheses grouped around the poem's centre, a lyrical celebration of Christ. ${ }^{13}$ In The Shape of Meaning in the Poetry of David Jones, Dilworth represents this diagrammatically with a series of nine concentric rings organised in the structure of a bull's-eye. He identifies this structure in a reading of the poem's content, which by necessity must to a degree thematically simplify each identified part of the poem. However, Dilworth's recourse to Jones's manuscripts is his killer blow: 'the manuscript evidence is indisputable', ${ }^{14}$ he writes. Method is taken as proof of form.

The evidence to which he refers is the scheme of foliation that Jones used to organise his manuscript. In moving from one parenthesis to the one enclosed within it (or which encloses it, depending on whether we read toward or away from the poem's centre) we move from one genetic stage in the making of the poem to another. In the first stage of this making, Jones produced an original eight-page fragment and then, splitting it at page five, made a large 20 page insertion into that base text which he foliated ' $5 \mathrm{~A}^{\prime}-{ }^{-} 5 \mathrm{~T}$ '. After doing this, Jones split his text again, within that ' $5 \mathrm{~A}$ '-' $5 \mathrm{~T}$ ' insertion, at page ' $5 \mathrm{~F}$ '. This second insertion was 33 pages long, and foliated '5F1''5F33'. Feeling perhaps that this foliation scheme was becoming unwieldy, Jones then re-paginated his manuscript from 1 to 74 . Following this, he went on to make another five insertions to his manuscript, starting with a '37A'-'37Q' insertion, with the effect that the last insertion he made to the manuscript was foliated '37.P.5.O.B.1'-'9'. ${ }^{15}$ The 'centre' of the poem in manuscript is eight insertional stages from the outer parenthesis, which exactly corresponds with Dilworth's thematic reading of the text. ${ }^{16}$

The first splitting of the text performed by Jones is presented by Dilworth as his 
greatest discovery, and one which he seized upon as the method by which he could give significant form to his emerging poem: 'in its creative potential and imaginative results, it was, for David Jones, an act as momentous as splitting the atom'. ${ }^{17}$ For Dilworth The Anathemata is an intentionally created formal sign for David Jones's paradigmatic sign, the Eucharist: 'in its paradoxical equation of centre and circumference, the poem's structure symbolically corresponds to the sacrament with which it is coextensive'. ${ }^{18}$ Tom Goldpaugh agrees with Dilworth's account of the making of the poem:

As the manuscripts to The Anathemata show...Jones began with a unified narrative which he then split, and into which he placed another section which was subsequently followed by a third insertion, and a fourth and so on. ${ }^{19}$

This method of making is again interpreted as being informed by a formal intention: in Goldpaugh's view, The Anathemata is a 'meta-sign'"20 whose intended form directed the method of its making; 'his insertional method...is inseparable from the force that engendered it: his desire to preserve the signa of the culture within a verbal temenos ${ }^{21}$ Both Dilworth's and Goldpaugh's conclusions - even if they differ as to what the form of the poem means - agree that its form is parenthetical, a judgement which is put beyond doubt by the foliational code of the manuscript, whose structure, in turn, is the irrefutable trace of the process of the poem's making. Their judgements would indeed appear to be unassailable as regards Jones's method. However, this reading of the foliational code is mistaken for two reasons. Firstly, the foliational code is far more complex than Dilworth and Goldpaugh let on. A true diagrammatic representation of the foliational code of the poem [Fig. 1] reveals that insertions were not only being made within the centres of preceding insertions, and therefore that the shape of the poem's making does not at all tally with the 'concentric rings' or parenthetical spatial form detected by Dilworth. This undermines Dilworth's and Goldpaugh's neat and tidy reading of the poem's spatial form through its process of becoming. 


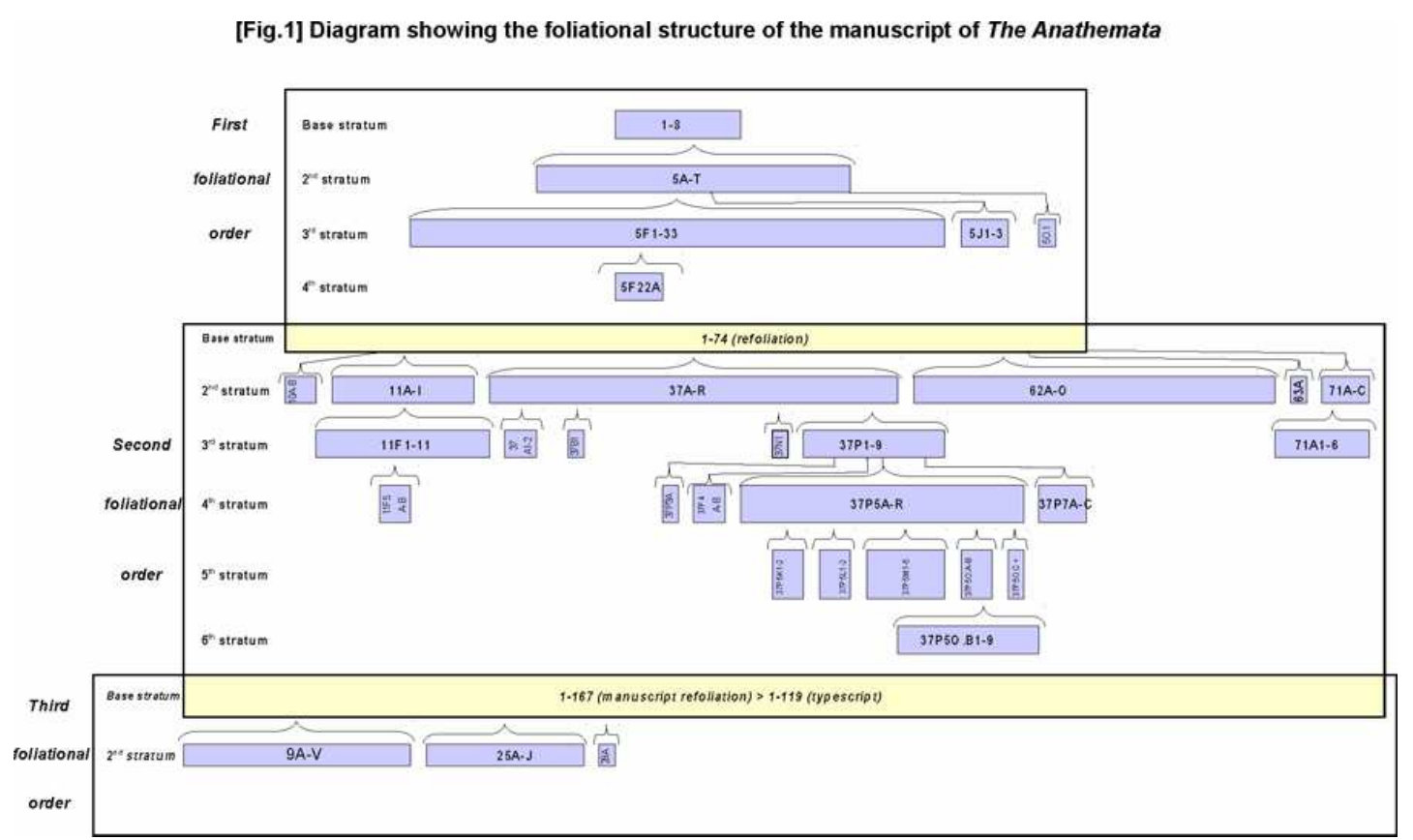

Far more significant, however, is the second reason: the insertions which Jones made to his text are not equivalent to the foliational strata visible in the diagram; each foliational stratum is composed of a huge number of minute, genetically interdependent insertions. The truth of the matter is that the critical reliance upon the foliational code for a reading of the poem's intended form is misguided because Jones's code was an effect of his way of working, not that way of working in itself. The manuscript evidence is indeed indisputable, but only if we consider its textual mess as well as its foliational order. The critical move to a consideration of this mess enables us, as Trotter makes clear, to reveal that Jones's method, far from being deterministic, relied upon chance.

\section{The Messy Making of The Anathemata}

In his Preface to The Anathemata, Jones compares the writing of his book to the movement of his mind:

In a sense the fragments that compose this book are about, or around and about, matters of all sorts which, by a kind of quasi-free association, are apt to stir in my mind at any time.

This 'quasi-free association' relies on the action of 'mental associations, liaisons, meanderings to and fro, "ambivalences", asides, sprawl of the pattern, if pattern there is.' This process is one that has an origin, for 'quasi-free association' cannot generate itself out of nothing:

[. . . ] these thought-trains (or, some might reasonably say, trains of distraction 
and inadvertence) have been as often as not initially set in motion, shunted or buffered into near sidings or off to far destinations, by some action or word, something seen or heard, during the liturgy. (Ana 31-32)

When Jones began inserting material into the 8-page base fragment of The Anathemata in 1945, he made those insertions based on the suggestiveness of the text contained within that fragment. Fittingly, the part of the fragment which first began this chain of inadvertence concerned the institution of the Eucharist by Christ in the Cenacle. $^{22}$

In the draft sheets which comprise the first foliational stratum (MS pp.5A-T) of the first foliational order (MS pp.1-8) (which equates to the beginning of what Dilworth and Goldpaugh call the 'first insertion'), Jones reconnects with the text of the original fragment on pages '5A', '5B' (in one case, Jones alters '5B' to '5C' as the draft is shunted down by further insertions), '5D', '5J', '5K' (becoming, first, '5M', then '5N'), '5O' and finally ' $5 \mathrm{~T}^{\prime}{ }^{23}$ At its shortest, the insertion is only ten lines long; in the final version, the insertion is of hundreds of lines. The supposedly monolithic 'first insertion' is actually a series of hundreds of intertwined insertions that developed out of an eight-page fragment that had itself been produced in this way. Thus, the division of the process of the making of the poem into stages that follow the lineaments of the foliational code is a simplification. The crisp division of the making of the poem into separate stages that the advent of the first foliational stratum at ' $5 \mathrm{~A}$ ' implies tidies up a messy reality in which Jones's text was generating out of itself in a mass of associations across this apparent division. ${ }^{24}$

Posed with the double-edged problem of the apparent simultaneous necessity and impossibility of a firm, preconceived structure - that the presence of such a thing would impose a simplified shape upon the ideas that lay behind his writing; but equally that its absence would plunge him into a stultifying total freedom - Jones worked new parts of his text out from the ground matter of his already existent text in a process of 'quasi-free association'. Thus we see Jones's description of the emergent form of his poem as being 'determined by the inner necessities of the thing itself' ${ }^{25}$ to be a wholly literal statement of how he produced that poem: it was the only practical alternative to the impasse of the 'outer necessity', or preconceived structure. Jones's micro-insertional method was the new 'chain' or ligament which would secure for Jones's making the freedom for quasi-free association to function, because, every time Jones began an insertion, there was always the same point in the text from which he departed to return to.

The table below [Fig. 2] shows five variant versions of pages 5A-D within the first foliational order of the manuscript of The Anathemata. The second-from-right column contains the text of the final manuscript version of the poem, split into separate cells in accordance with line breaks. ${ }^{26}$ The first to fourth columns to the left of that final version show the succession of drafts Jones made whilst writing within the foliational 
order 5A-T. The first 11 lines of text (down to the shaded row) comprise the lead-in for the insertion as transcribed from page five of the 'base' fragment (this is why they are the same for all draft versions). As the table shows, the first extant 5A draft (far left column) is inserted into the space - indeed the act of insertion creates that very space - of an already existent text concerned with the Cenacle. This first draft is then split in the subsequent second draft by insertions which re-call further 'deposits', and so on in the third and fourth drafts. It is manifestly the case that each of these insertions was not part of one large insertion (5A-T); far from building upon each other in a textual sequence, each insertion takes place within its predecessor in a textual tangle. 


\begin{tabular}{|c|c|c|c|c|c|}
\hline \multicolumn{5}{|c|}{ Base stratum text } & DEPOSIT \\
\hline & \multicolumn{4}{|l|}{ Page 5/LA1/2.7] } & \multirow{17}{*}{$\begin{array}{l}\text { Institution of the Eucharist in the } \\
\text { Cenacle, thought by some to have } \\
\text { stood on Mount Zion in } \\
\text { Jerusalem. }\end{array}$} \\
\hline & \multicolumn{4}{|l|}{ In the prepared hightroom } & \\
\hline & \multicolumn{4}{|c|}{ he implements, inside time \& late in time } & \\
\hline & \multicolumn{4}{|c|}{ under forms indelibly marked by locale } & \\
\hline & \multicolumn{4}{|c|}{ and incidence, deliberations made out } & \\
\hline & \multicolumn{4}{|c|}{ of time, before all <oreogenesis> } & \\
\hline & & & & Pago 5A [LA1/28.8] & \\
\hline & \multicolumn{3}{|l|}{ 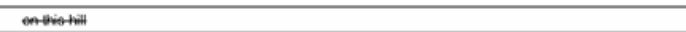 } & on this hill & \\
\hline & \multicolumn{3}{|l|}{ 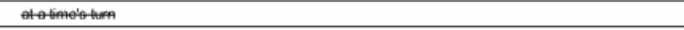 } & \begin{tabular}{|l} 
at a fime's tum \\
\end{tabular} & \\
\hline & \multicolumn{3}{|l|}{ 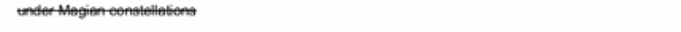 } & & \\
\hline & 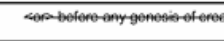 & & & & \\
\hline & Notentamytith & & & not on any hill & \\
\hline & 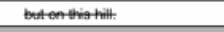 & & & but on this hill & \\
\hline & & First foliational stratum text & & & \\
\hline$f^{\text {st }}$ drafti & $2^{\text {nd }} \mathrm{draft}$ & $3^{d}$ dratt & 4 draft & Final manuscript & \\
\hline Page 5A /LA1/23.190.V" & [no psge number, LA1/4.3] & Page 5A [LA1/4.4] & Pege 5A [LA1/4.5] & As above, continued & \\
\hline [on this unstable \& [...] [m]Jumlain & $\begin{array}{l}\text { on this impermanent rock } \\
\text { on }\end{array}$ & $\begin{array}{l}\text { on this senabiding> } \\
\text { rock }\end{array}$ & on this unabiding rock & IOn this unabiding rock & \\
\hline [.... ne brief Great Summerf..] & (for one Great Summer & (for one Great Summer & ffor one Great Summer & for one Great Summer & \\
\hline & lifted up. & lifted up & lifted up & \begin{tabular}{|l|} 
lifted up \\
\end{tabular} & \\
\hline by next Graat Winter & by next Great Winter & by next Graat Winter & by next Great Winter & by next Great Winter & \\
\hline [...] down & with Tauras, down & down, & down & down, & \\
\hline & & among the altitudes & among the altitudes & among the altitudes & \\
\hline $\begin{array}{l}\text { [...]made help-heights, Foel } \\
\text { Cria[...] }\end{array}$ & flumbled with Pyreneus, ${ }^{\prime}$ & \{with Feungroblebanus>\} & with all help-heights & with all help heights & $\begin{array}{l}\text { Aristotit's theory of cimatic and } \\
\text { geological change }\end{array}$ \\
\hline & & down & down & down & \\
\hline & \{Allas\} & \begin{tabular}{|l|l} 
as low as Olympus \\
\end{tabular} & as low as Pamassos & as low as Pamassos & \\
\hline & Pelion under Ossa & Ossa on Pelion now & It's Ossa on Pelion now & (it's Ossa on Pelion now) & \\
\hline & with Semptimontium & Coeli & Seven templum'd montes & Seven templum'd montes & A connection between Roman \\
\hline & & under larging middle-sea & under terra-mart & under terra-marl & and $P_{0}$ Valley seltuements \\
\hline & senai & Senai under & Senai under & \begin{tabular}{|l|} 
Senai under \\
\end{tabular} & Noah's ark's landing point. \\
\hline & & where's ark hill? where Taunus? & where's ark-hill? & where's Ark-hill? & \\
\hline along with the two Idas & & & ask both the Idas. & ask both the Idas. & Mountains in Troass and Crete \\
\hline & & & And where: & And where: & \\
\hline & west horse-hills & $\begin{array}{l}\text { west horse-hills, separate west- } \\
\text { tumuli }\end{array}$ & west horse-hills? & West horse-hills? & \\
\hline & the caimed myryddoedd. & Volcae-remnant's tall caerau & Volcae-remnants' cameddau? & $\begin{array}{l}\text { Volcae-remnants' crag- } \\
\text { cameddau? }\end{array}$ & Welsh mountains \\
\hline $\begin{array}{l}\text { \{Horeb, Ablan, may Mofel of the } \\
\text { mothers?]\} }\end{array}$ & & & & moel of the mothers? & \\
\hline $\begin{array}{l}\text { [...]ad Arther, Upsala hill, Tara[...] } \\
\text { \& eadch high tumulus - [...] }\end{array}$ & \{all the high tumulit\} & & & the many colles Anctur? & \\
\hline & & all the efficacious asylums & all the efficacious asylums? & all the efficacious asylums? & \\
\hline & & & & $5 B$ [LA $1 / 8.9]$ & \\
\hline & & even Hissartik-height & Hissarlk? & Nine-strata'd Hissarlik & \\
\hline & & & (but forty metre height & (a but forty-metre height & \\
\hline & & archetype of sung-heights & yet archetype of sung heights) & yet archetype of sung heights) & \\
\hline & & & & crux-mound at the node & \\
\hline & & & & gammadion'd castle & \\
\hline & & & & (within the laughless Megaron & \\
\hline & & & & the margaron $[\ldots]$ & \\
\hline & & & & $\begin{array}{l}\text { [25 lines focusing on 'Hissarlik' } \\
\text { omitted]] }\end{array}$ & Troy \\
\hline & & & & [...fllonid she breached & \\
\hline & & & & with spume on her spear-flukes, & \\
\hline & & & & the great fluked marmals blow; & \\
\hline & & & & glaciation cones her own Thebes & \\
\hline & & & & Loess drifts Leo-gate. & \\
\hline & montes & all monies & All montes & All montes & \\
\hline [...Jmade help heights, [..] & with the dear-made help heights & with the dear made help-heights & with each dear made-height & with each dear made-height & \\
\hline [.... Jomnes colles. & et omnes colles & et omnes colles & et omnes colles. & et omnes colles & \\
\hline & & & down. & down & \\
\hline & & & hautes eagle-heights under & hautes eagle-heights under & \\
\hline & & & low as lark-slope on Lamboum & low as Lamboum Down & \\
\hline & & & $\begin{array}{l}\text { [5B LA1/4.8] } \\
\text { As solitary tump, so massif }\end{array}$ & As solitary tump, so massif? & \\
\hline & & Allas as with Bredon & Alp, as Bredon & Np, as Bredon, & Summary link between gealogical \\
\hline & & & down & down & and climatic change. \\
\hline & obecient to the rthythm, & odedient to the & obedient to the fery stour-drag & obecient to the fiery stress & \\
\hline & & icy mythm, & and icy counter-drag & und icy counter-drag & \\
\hline & down.) & down) & down, and. & down, and, & \\
\hline & & & there shall be yet more & there shall be yet more & \\
\hline & & & stom-dark sea) & \begin{tabular}{|l} 
storm-dark sea \\
\end{tabular} & \\
\hline & & & & my Lord! what a moming breaks & \\
\hline & & & & on this new-founded & \\
\hline & & & & oberliand & \\
\hline on this fleeting $h[$ [il] & on this transitory mountain & on this unabiding mountain & On this fleeting mountain & On this fleeting mountain & \\
\hline [at] a times urm & within fleeting time[...] & $\begin{array}{l}\text { within fugitive bime, and, at a } \\
\text { time's tum(...] }\end{array}$ & at the Tum of Time[...] & & Return to the Cenacle \\
\hline
\end{tabular}

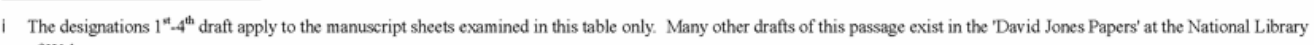
of Wales.

ii The lacunae in the text on folio LA1/23.190.v, indicated with elipses in square brackets, are due to the page being torn.

iii Curly brackets indicate a probable but not certain 'identity' with the same line of the fimal manuscript version 
In this particular case, I believe that, as Jones read over his 'original' eight-page fragment, the hill upon which the Cenacle stood chanced to suggest to him Aristotle's theory of the Great Summer and the Great Winter. Although Christ's institution of the Eucharist in the Cenacle is beyond human or geological time ('deliberations made out / of time, before all oreogenesis'), that action must take place at a specific time ('at a time's turn') in a specific place ('not on any hill / but on this hill'). The impermanence of the physical world, no matter how awesome its geological history is in striking the imagination, starkly contrasts with the eternity of Christ's action. Aristotle's theory appears to be suggested to Jones as a way of emphasising the notion of eternity stepping into time which Christ effects. The hill of Jerusalem is 'impermanent'; for '[o]ne brief Great Summer' it is lifted up; 'by next Great Winter[. . .]down' (LR1/23.190.v). Christ must step into human time and place, into a now, and institute the Eucharist in our terms. Even the greatest human mind - Aristotle's, as far as Jones is concerned; a mind which can predict the discovery of the history of the earth (Jones tells us in his notes that Aristotle's theory 'is largely verified by modern physical science ${ }^{27}$ ) - cannot envisage the real presence of the Eucharist. 'Rite and Fore-Time', the first part of The Anathemata, is largely concerned with pre-Christian rites, and with the salvation of the makers of those rites by pre-application (see Ana 65). As far as Jones was concerned, Aristotle would be first in the queue for such salvation. I believe, therefore, that the hilltop Cenacle suggests the geological movement implicated in Aristotle, Thomas Aquinas's great secular prophet of Christianity. All of this, I would suggest, occurred in an instant, and of course contained a far greater complexity of significance than is possible accurately to account for here. But I hope that what is clear from this is that the action which took place in this single moment as a result of Jones's re-reading was entirely dependent upon chance association at that particular makerly moment.

After the reference to Aristotle, this first draft goes on to list various hills or mountains, and then returns to the 'fleeting h[ill]' in Jerusalem. In the second draft, more and more hills enter the text. In the third, Jones reads back his second draft and finds the hill upon which Troy was built suggested to him. As a result, the two lines 'even Hissarlik-height / archetype of sung-heights' enter the text, though this is all there is of Troy in the poem for the moment. The reference to Troy/Hissarlik takes place within the terms of the previous draft, simply as part of a list of hills (though it is 'even' Hissarlik, Troy having a special place in the history of Western literature as its first city). By the time the final manuscript is drafted, the Hissarlik reference has grown into a thirty-line passage exploring the cultural importance of Troy in the Western tradition; and yet Troy only entered the text by chance, which relied upon Aristotle's theory - which itself had entered the text by chance. ${ }^{28}$

The repeated opening of the text to take in more of Jones's deposits demonstrated by this account is by no means an isolated case. This was the very foundational method 
for the writing of the whole of The Anathemata. His method of quasi-free association, which was made sustainable by departing from and returning to the text in minute, incremental makerly motions (Jones's necessary 'ligament') enabled the generation of an enormous poem out of a single five-page fragment: when Jones sent off his manuscript for typing in 1949, it was 197 pages long. ${ }^{29}$

\section{The Meaning and Value of Chance}

Jones's method of writing produced a poem which is, in his own words, 'a somewhat different cup of tea' ${ }^{30}$ Writing to William Hayward five years after the poem was published, Jones stated that

[. . . ] it seems to me, as far as I can tell, that you have got hold of the kind of thing that The Ana tried or, rather, happened, to be. I say 'happened' because it would be a great mistake to suppose it was a planned work. ${ }^{31}$

The form of the poem, then, is a corollary of an unintentioned method: like mess, it just happened. In another letter to Hayward written two months later, we see that the form of the poem isn't like mess - it is mess:

It is a disadvantage of my method (or lack of it!) that the reader is faced with rather sudden $\&$ unwarned of changes of occasion, and that causes confusion...It is a weakness of my technique that these changes are insufficiently marked. ${ }^{32}$

Jones's method allowed him to write his non-narrative poem about ideas, but his messy process results to a certain extent in an unintended and even unwanted shape a readerly mess. But is it really?

The amphibolic structure of the title - a sign for the aporia Jones felt for contemporary culture - is repeated throughout the poem in numerous paradoxical formulations. ${ }^{33}$ In addition to this, the only description by Jones which indicates a positive take on the form of The Anathemata - one which does not imply mess brings to light a further aspect of structural repetition: '[i]f it has a shape it is chiefly that it returns to its beginning' (Ana 33). Jones's micro-insertional method was built upon this motion; his entire text was constructed with small textual insertions; it was continually departing from and then returning to itself; it was built out of hundreds, perhaps thousands, of returnings-to-its-beginnings. With both these makerly considerations in mind, I would suggest that the resultant effect on the form of the poem does indeed make it into a kind of labyrinth, but only by accident. The highly complex labyrinth of The Anathemata was generated out of a simple process in 
repetition. The spatial metaphor I would like to suggest for the form of The Anathemata is the fractal because this metaphor stresses the irregular, fragmentary state of the poem, its formal 'self-similarity', its self-replicating genesis, but most importantly in the current context, the fractal is analogical to Jones's poem through its ultimate form both residing in and being unimaginable at the base level of its generation - its final shape appears as if by chance.

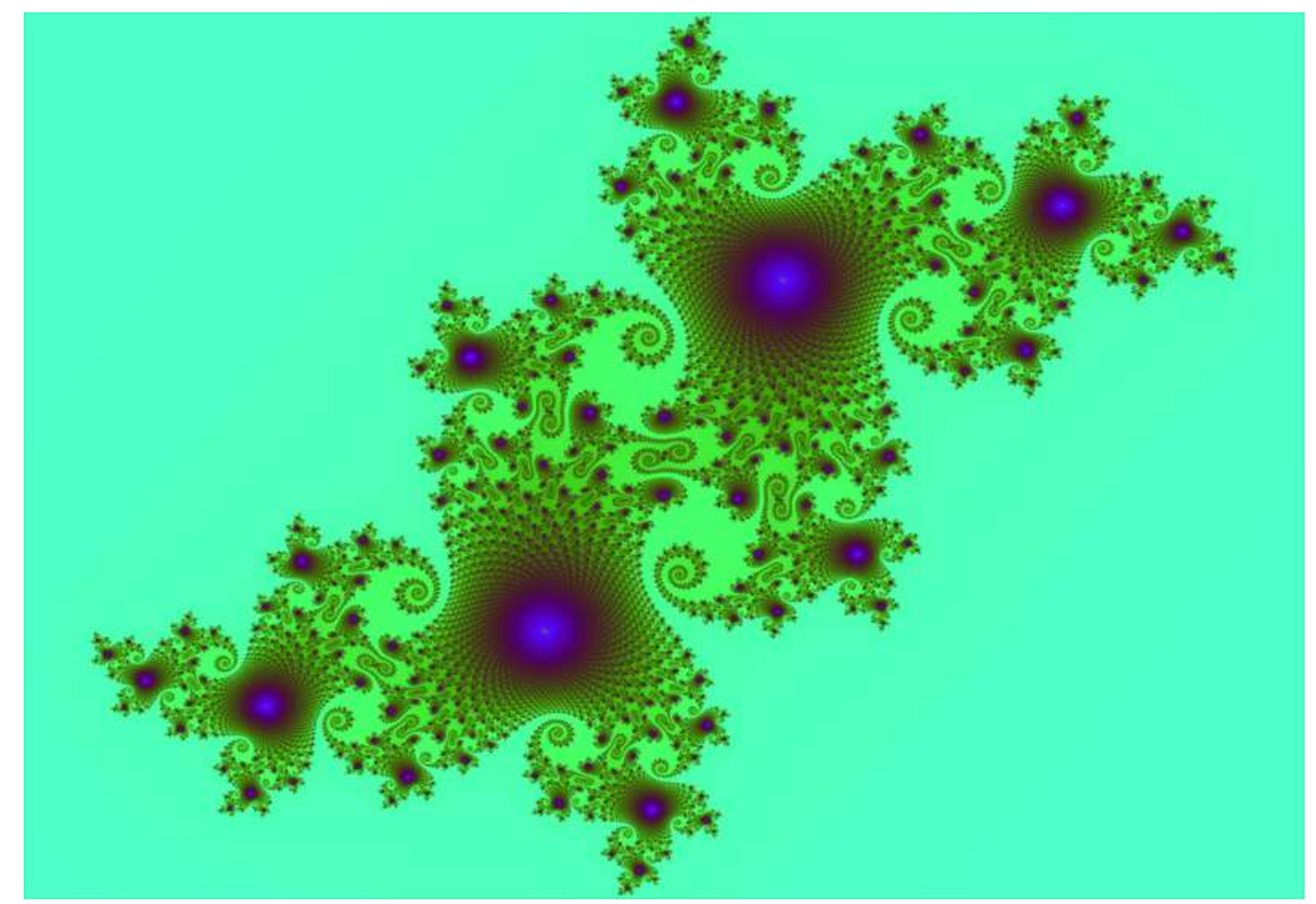

An example of a Julia set fractal

If fractals can be strikingly beautiful, an important additional characteristic in this context is that they might very well not be beautiful; the complex visual shape generated by a repeated simple function is a surprise. 

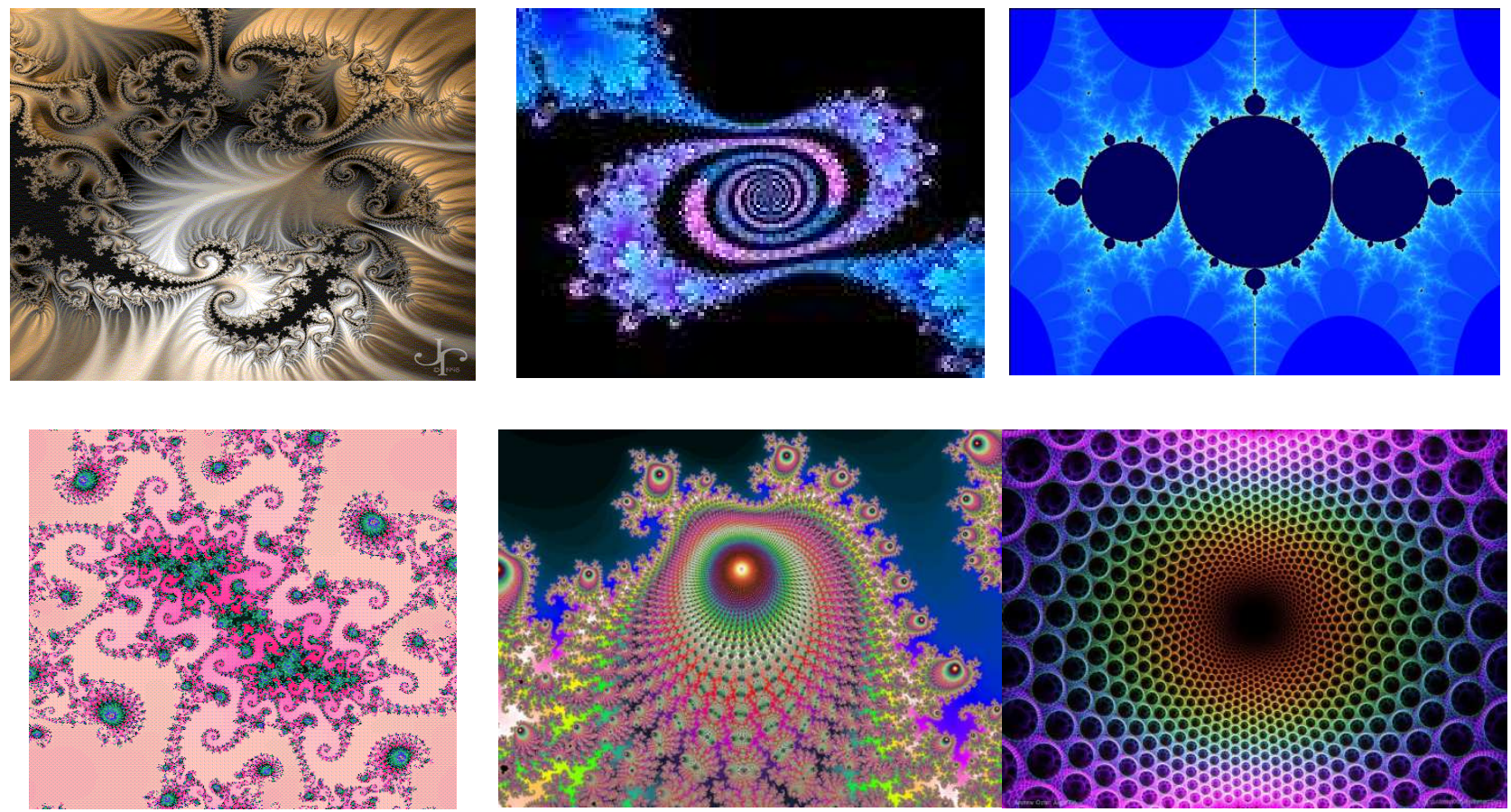

\section{Mandelbrot and Julia set fractals}

And it is here that the fractal is most apt in representing the form of The Anathemata, of whose success Jones was never sure during its making: the aesthetic quality of the overall pattern which arises is a game of chance; it may please, and it may not; in a sense its formal generation is entirely gratuitous. The form of The Anathemata as a beautiful mess was possible because of the gratuitousness which inhered to its writing. I would suggest that the poem's making asserts a meaning and value for chance: by enabling the gratuitous production of a literary work, chance, the core generative principle of Jones's discovered method, can be seen as a device for proclaiming the very meaning and value of being human through enabling a making to occur under seemingly impossible conditions.

\section{PAUL STANBRIDGE}

Paul Stanbridge is a PhD candidate at the University of East Anglia. His thesis investigates the process by which David Jones wrote The Anathemata.

\footnotetext{
${ }^{1}$ Letter to Harman Grisewood, 31 May 1938; in David Jones, Dai Greatcoat: A Self-Portrait of David Jones in His Letters, ed. by Rene Hague (London and Boston, Mass.: Faber and Faber, 1980), p. 86;
} 
hereafter referred to as $D G C$.

${ }^{2}$ David Jones, 'Art and Sacrament' (1955), Epoch and Artist (London: Faber and Faber, 1959), p. 158; hereafter referred to as $E \& A$.

${ }^{3} \mathrm{He}$ does this on pages $143,144,145,147,153,154,176,177,178,185: E \& A$.

${ }^{4}$ David Jones, The Anathemata (1952), (London: Faber and Faber, 1972), p.25; hereafter referred to as Ana.

${ }^{5}$ See Ana 15, as well as Jones's earliest statement of this idea in his Preface to In Parenthesis (London: Faber and Faber, 1937).

${ }^{6}$ MS p. 1 [second draft], LR8/6.2, 'David Jones Papers', The National Library of Wales (NLW). All subsequent references to individual sheets from the manuscripts of The Anathemata state Jones's page number(s) and then the NLW classification reference number. Arrowed brackets denote insertions Jones has made to the text; the crossings out are, of course, Jones's.

${ }^{7}$ Jacques Maritain, 'The Frontiers of Poetry' in Art and Scholasticism (London: Sheed \& Ward, 1930), p. 91. For an account of the importance of Maritain to Jones, see Thomas Dilworth, 'David Jones and the Maritain Conversation', in David Jones: Diversity in Unity: Studies in His Literary and Visual Art, ed. by A. Price-Owen and Belinda Humphries (Cardiff: University of Wales Press), pp. 45-55.

${ }^{8}$ David Trotter, Cooking With Mud: The Idea of Mess in Nineteenth-Century Art and Fiction (Oxford: Oxford University Press, 2000), p. 10.

${ }^{9}$ Ibid.

${ }^{10}$ Trotter notes that, after Darwin, providence and fate, which turn chance into non-chance, were increasingly untenable. The epistemological hollow left by their recession allowed psychoanalysis to emerge, which, as Trotter notes, systematically inscribes chance (though of course not all chance) within subconscious desire. See Cooking With Mud, pp. 137-43 (on providence and Darwin) and pp.10-12 (on Freud, psychoanalysis and chance).

${ }^{11}$ Ibid. p.10.

${ }^{12}$ The form of the poem is said to resemble Celtic art (Gwyn Williams), a labyrinth (Jeremy Hooker), a series of concentric rings (Thomas Dilworth), or a unicursal labyrinth (Thomas Goldpaugh). See Thomas Dilworth, The Shape of Meaning in the Poetry of David Jones (Toronto: University of Toronto Press, 1988), pp. 154-56; and Thomas Goldpaugh, 'Mapping the Labyrinth: The Ur-Anathemata of David Jones', in Renascence: Essays on Values in Literature, vol. 51, no. 4 (pp.253-80); p. 269.

${ }^{13}$ See Thomas Dilworth, 'From The Deluge to The Anathemata: Engraving Towards Poetry', in David Jones: Artist and Poet, ed. by Paul Hills (Aldershot: Scholar Press, 1997), pp. 44-45.

${ }^{14}$ Dilworth, 'From The Deluge to The Anathemata', p. 45.

${ }^{15}$ The eight foliation stages (in simple terms) are: (i) 1-8, (ii) 5A-T, (iii) 5F1-33, (iv) 37A-R, (v) 37P19, (vi) 37P5A-R, (vii) 37P5O.A-C, and (viii) 37P5O.B1-9. We will see in due course why this is only 'in simple terms'.

${ }^{16}$ See Dilworth, 'From The Deluge to The Anathemata, pp. 44-45.

${ }^{17}$ Dilworth, The Shape of Meaning, p. 171. Nearly a decade later, Dilworth states that this 'discovery' had already been made by Jones in the making of the engravings for The Deluge (1927) nearly two decades before making this discovery. See Dilworth, 'From The Deluge to The Anathemata', pp. 47-51. ${ }^{18}$ Dilworth, The Shape of Meaning, p.172.

${ }^{19}$ I quote here from a draft version of Thomas Goldpaugh's as yet unpublished essay 'To Make (and Unmake) A Shape in Words: David Jones and the Continuation of The Anathemata: fragments of an attempted writing'.

${ }^{20}$ Goldpaugh, 'Mapping the Labyrinth', p. 255.

${ }^{21}$ Ibid., p. 275.

${ }^{22}$ The 'base' fragment of The Anathemata first had its beginning and ending established in a five-page version (for this ending, see MS p.5 on NLW folio LA1/23.3). This grew to become an eight-page fragment through the insertion of material meditating on Christ's institution of the Eucharist as only being possible within the terms of rites undertaken in the culture in which he lived (see, amongst others, NLW folios LA1/3.11, LA1/8.7, LA1/3.16, LA1/23.5, LA1/3.19). This eight-page version is the stable basis for the insertions that took place using a foliational code.

${ }^{23}$ These are found on the following manuscript sheets in the NLW folios: LA1/23.190.v, LA1/4.1, LA1/4.3, LA1/4.4, LA1/4.8, LA1/4.10, LA1/8.11, LA1/4.180-183, LA1/4.208, LA1/4.218-219 and LA1/9.139.

${ }^{24}$ The length of the first ' $5 \mathrm{~A}$ ' insertion - 14 lines - makes it significantly smaller than the 25 -line one that was subsumed into the emerging structure of the first fragment (see the insertion of material on unpaginated folio LA1/3.10 into page 4 (folio LA1/3.9) of Jones's manuscript). As already stated (see note 22) the eight-page base fragment was originally a five-page base; the way in which this became 
eight pages long was through the accretion of insertions. The insertions that enacted this growth are genetically identical to the preliminary insertions to the eight-page fragment that are foliated 5A onwards. This in itself refutes the idea that Jones premeditated a meta-sign in the form of his poem, for it shows that the foliational code was merely a reaction to textual growth, and the divisions between foliational stages are not at all divisions between insertional stages.

${ }^{25}$ Letter of 29 December 1952 in David Jones, Inner Necessities: The Letters of David Jones to Desmond Chute, ed. by Thomas Dilworth (Toronto: Anson-Cartwright Editions, 1984), p. 24.

${ }^{26}$ It is noticeably different to the published version - see pp. 55-58 of The Anathemata.

${ }^{27}$ The Anathemata, p. 54, note 1.

${ }^{28}$ This could not have happened had not Troy been excavated and identified beneath modern Hissarlik by Frank Calvert (in the 1860s) and Heinrich Schliemann (in the 1870s). Here, we see a very clear-cut example of how The Anathemata was dependent upon discoveries being made within other disciplines. ${ }^{29}$ The final manuscript to The Anathemata is contained in NLW files LA1/8 and LA1/9. The first of these contains MS pp. 1-73; the second MS pp. 44-166. The overlap of numbers between MS pp. 4473 is baffling, but the sequence is correct, as can de discerned by referring to the Jones's two earlier foliational codes. The final two pages are missing (MS pp.167-8). Taking into consideration the overlap of pages 44-73 and the two missing sheets, Jones's completed manuscript was 197 pages long. ${ }^{30}$ David Jones, in an unpublished letter written to Jim Ede shortly before the publication of The Anathemata, 18 October 1952 at Kettle's Yard, Cambridge.

${ }^{31}$ Letter of 10 December 1957 in David Jones, Letters to William Hayward, ed. by Colin Wilcockson (London: Agenda Editions, 1979), p.16.

${ }^{32}$ Letter from 3rd and 6th February 1958, in Jones, Letters to William Hayward, p. 38.

${ }^{33}$ For an account of Jones's title, see Ann Carson Daly, 'The Amphibolic Title of The Anathemata: A Key to the Structure of the Poem', Renascence: Essays on Values in Literature, 35.1 (1982), 15-30. Some examples of Jones's use of paradoxical formulations from the very first page of The Anathemata: 'already and first of all' in relation to the becoming of man is a logical impossibility; 'pasteboard baldachins' is, literally, an oxymoron; as is 'sterile ornaments' at the Mass, for these ornaments are supposed to be life-giving. Throughout the poem, the identity of the Eucharist, Incarnation, and Crucifixion is dwelt upon, and each of these is valued in large part for being a logical paradox. 